\title{
Uso do Ester cianoecrilato como auxiliar na fixação de dispositivo intravenoso periférico em coelhos submetidos a procedimentos cirúrgicos experimentais
}

\author{
Use of the ester cianoacrilate as to auxiliary in the fixation of the device peripheral \\ venous administration in submitted rabbits the experimental surgical procedures \\ Luiz Antônio Franco da Silva ${ }^{1}$, Andréia Vitor Couto do Amaral ${ }^{1}$, Duvaldo Eurides ${ }^{2}$, \\ Rogério Elias Rabelo ${ }^{3}$, Leandro Franco Guimarães ${ }^{1}$, Maria Ivete de Moura ${ }^{1} \&$ Lorena Karine Soares $^{1}$
}

\begin{abstract}
RESUMO
O experimento foi realizado no Hospital Veterinário da Universidade Federal de Goiás, Goiânia, GO/Brasil, utilizando-se 40 coelhos machos, peso médio de 2,6 quilogramas, da raça Nova Zelândia (Oryctolagus cuniculis), na faixa etária de cinco meses. Os animais foram distribuídos aleatoriamente em quatro grupos de dez (GI, GII, GIII e GIV). Nos animais pertencentes ao grupo I (GI) a veia marginal do pavilhão auricular foi canulada utilizando-se cateter de politetrafluoretileno, os animais que compuseram o grupo II (GII) procedeu-se a canulação com scalp tipo butterfly. Em ambos os grupos, aplicouse na pele da superfície dorsal da orelha e na superfície ventral do cateter ou scalp, cola éster de cianoacrilato. Nos animais pertencentes aos grupos III (GIII) utilizou-se cateter, e no grupo IV (GIV) utilizou-se scalp tipo butterfly, ambos fixados com esparadrapo. Durante o período de observação, os dispositivos não permaneceram no leito vascular em dois coelhos pertencentes ao GI, três do GII, três do GIII e em cinco animais que compuseram o GIV, sendo que os deslocamentos foram observados após interromper o procedimento anestésico. Constatou-se que o etil-cianoacrilato fixou adequadamente cateteres rígidos e flexíveis na veia auricular dorsal de coelhos, permitindo infusão venosa com segurança.
\end{abstract}

Descritores: cianoacrilato, coelhos, infusão venosa.

\section{ABSTRACT}

The experiment was done in the Veterinarian Hospital of the Universidade Federal de Goiás, Goiânia, GO/Brazil, and was used 40 male rabbits, average weight of 2,6 kilograms, the New Zealand (Oryctolagus cuniculis) race, in the age of five months. The animals had distributed in four groups of ten rabbits (GI, GII, GIII and GIV). In the pertaining animals to the group I (GI) the marginal vein of the auricular pavilion was did a venous administration using polytetrafluorethylene catheter, the animals that had composed the group II (GII) proceeded it venous administration with scalp type butterfly. In both that groups, used glue ester of cianoacrilate for applied the cateter and scalp in the skin of the dorsal surface of the auricular pavilion. In the pertaining animals to the group III (GIII) catheter was used, and in the group IV (GIV) scalp type butterfly was used, both was fixed with plaster. During the observation period, the devices had not staied marginal vein of the auricular pavilion of two the rabbit rabbits pertaining to GI, three of GII, three of the GIII and in five animals that had composed the GIV. The displacements had been observed after the interrupt of the anaesthesia. Venosa infusion with security was evidenced when the rigid and flexible catheters was fixed adequately with etil-cianoacrilato in the dorsal auricular vein of rabbits.

Key words: venous administration, rabbits, cianoacrilate. 


\section{INTRODUÇÃO}

Os coelhos são usados como modelo experimental por sua docilidade, custo, fácil manejo e obtenção e, quando utilizados em cirurgias experimentais, apresentam metabolismo acelerado dos anestésicos. Tal fato propicia recuperação imediata e progressiva ao estado normal de consciência, fazendo com que estes animais removam os cateteres venosos e os curativos aplicados às feridas cirúrgicas, desencadeando deiscência de ferida, hematomas, edemas e abscessos, comprometendo o sucesso das intervenções e o bem-estar animal.

Ao se utilizar coelhos em cirurgias, são fatores limitantes a escolha do anestésico, localização e diâmetro do vaso sanguíneo a ser canulado. Na contenção química e infusão de líquidos intravasculares, recomenda-se utilizar a veia marginal do pavilhão auricular externo. Dá-se preferência pelo cateter com agulha flexível, fixado com esparadrapo, uma vez que o scalp pode danificar o lúmen vascular [7]. Para minimizar as intercorrências advindas do rápido retorno de consciência após a anestesia, acredita-se que os adesivos à base de cianoacrilato sejam uma alternativa na manutenção de cateteres e scalps venosos em coelhos.

Os cianoacrilatos são adesivos não biológicos com características bacteriostáticas e hemostáticas resultando em menor reação de corpo estranho e inflamação, comparada à sutura convencional $[3,6,10,12]$. O éster de etil-cianoacrilato tem sido usado na síntese de tecidos, auxiliando na sutura e hemostasia, sendo os resultados animadores [10].

Objetivou-se neste estudo avaliar a capacidade adesiva e as possíveis intercorrências do emprego do éster de cianoacrilato na fixação de cateteres e scalps na veia auricular dorsal de coelhos.

\section{MATERIAIS E MÉTODOS}

O experimento foi realizado no Hospital Veterinário da Universidade Federal de Goiás, entre os meses de março e junho de 2007, utilizando-se 40 coelhos machos, peso médio de $2,6 \mathrm{~kg}$, da raça Nova Zelândia (Oryctolagus cuniculis), na faixa etária de cinco meses. As unidades experimentais foram distribuídas aleatoriamente em quatro grupos de dez (GI, GII, GIII e GIV) e mantidas em gaiolas apropriadas. Acrescente-se que todas as etapas experimentais obedeceram rigorosamente às orientações do COBEA, sendo o projeto aprovado pelo Comitê de Ética em Pesquisa da Universidade Federal de Goiás em 12/03/2007 (Protocolo 002/07).

A preparação dos animais para a realização dos procedimentos cirúrgicos experimentais constou de jejum completo de 24 horas, sedação e indução anestésica, empregando uma associação de $3 \mathrm{mg} / \mathrm{kg} / \mathrm{IM}$ de xilazina ${ }^{1}, 20 \mathrm{mg} / \mathrm{kg} / \mathrm{IM}$ de cetamina ${ }^{2}$ e $5 \mathrm{mg} / \mathrm{kg} / \mathrm{IM}$ de diazepan ${ }^{3}$.

Procedeu-se a tricotomia da região dorsal do pavilhão auricular direito seguida de higienização com éter e antissepsia com polivinilpirrolidona-iodo $(\mathrm{PVPI})^{4}$. Nessa ocasião, aferiu-se o diâmetro da concha auricular na altura da veia dorsal, local escolhido para se proceder a canulação, utilizando-se para tal manobra um paquímetro previamente autoclavado. Esse mesmo aparelho foi utilizado nas aferições subsequientes à remoção dos dispositivos intravenosos.

Nos animais pertencentes ao grupo I (GI) efetuou-se a canulação da veia marginal do pavilhão auricular utilizando-se um cateter de politetrafluoretileno, número 24 , com $0,67 \mathrm{~mm}$ de diâmetro e 19 mm de comprimento. Os coelhos que compuseram o grupo II (GII) tiveram a veia canulada com scalp tipo butterfly número 23. Logo após a canulação da veia, nos animais de ambos os grupos, aplicou-se, na pele da superfície dorsal da orelha e na superfície ventral do cateter ou scalp, aproximadamente um centímetro cúbico de cola éster de cianoacrilato ${ }^{5}$, visando fixação imediata dos dispositivos intravenosos à pele auricular. Quanto aos animais pertencentes aos grupos III (GIII) utilizou-se cateter com as mesmas especificações do dispositivo empregado no GI. Nos coelhos do grupo IV (GIV), utilizou-se scalp tipo butterfly número 23. Nos animais de ambos os grupos, utilizouse na fixação dos dispositivos o esparadrapo.

Os coelhos foram submetidos à anestesia geral por 30 minutos, utilizando-se as mesmas drogas empregadas na sedação e indução, porém administradas por via intravenosa. Concomitante, realizou-se fluidoterapia a base de solução de cloreto de sódio a $0,9 \%^{6}$, empregando-se equipo tipo micro-gotas. Após este período manteve-se a fluidoterapia por mais 60 minutos. Durante a permanência do cateter ou do scalp no leito vascular, avaliou-se a capacidade do adesivo éster de cianoacrilato e do esparadrapo em mantêlos fixados à pele auricular. Decorrido então esse tempo, os dispositivos intravenosos foram imediatamente removidos. 
O local da orelha onde canulou-se a veia auricular dorsal foi avaliado antes de se proceder a canulação, logo que se efetuou a remoção do cateter ou do scalp, 24, 48 e 72 horas após sua remoção. Esses tempos foram denominados respectivamente, momento zero (M0), um (M1), dois (M2), três (M3), quatro (M4) e cinco (M5). Os principais parâmetros avaliados foram presença de hematoma, edema e abscesso, os quais foram classificados de acordo com a gravidade do problema. Independente da intercorrência considerou-se como leve, quando a espessura da concha auricular aumentou em até $10 \%$, moderado os casos que atingiram entre 10 e $20 \%$ e grave quando o aumento na espessura do pavilhão auricular no local de aplicação dos dispositivos foi superior a $20 \%$.
Os dados obtidos foram analisados por meio de tabelas empregando-se estatística descritiva, conforme metodologia de Monteiro Filho [10].

\section{RESULTADOS}

Durante os 90 minutos de observação, incluindo o tempo de anestesia, os dispositivos não permaneceram no leito vascular em dois (20\%) coelhos pertencentes ao GI, três (30\%) do GII, três (30\%) do GIII e em cinco (50\%) animais que compuseram o GIV. Em todos os casos a retirada do dispositivo foi efetuada pelos próprios animais e ocorreu em média, trinta minutos após a suspensão do procedimento anestésico.

Conforme apresentado na Tabela 1, observase que de um total de 37 intercorrências durante o

Tabela 1. Relação de intercorrências observados na região dorsal da concha auricular de coelhos, durante e após a aplicação de cateter e scalp intravenoso, de acordo com o grupo e o momento de observação, no período compreendido entre março e junho de 2007.

\begin{tabular}{|c|c|c|c|c|c|c|c|c|c|c|}
\hline \multirow{2}{*}{ Grupo } & \multirow{2}{*}{$\begin{array}{l}\text { Dispositivo } \\
\text { empregado }\end{array}$} & \multirow{2}{*}{ Intercorrências } & \multicolumn{8}{|c|}{ № de animais/momentos observados } \\
\hline & & & MO & M1 & M2 & М3 & M4 & M5 & Total & TOTAL (\%) \\
\hline \multirow{4}{*}{1} & \multirow{4}{*}{ cateter } & $\begin{array}{l}\text { deslocamento } \\
\text { do cateter }\end{array}$ & 2 & - & - & - & - & - & 2 & 5,4 \\
\hline & & hematoma & - & 1 & - & - & - & - & 1 & 2,71 \\
\hline & & edema & - & 1 & 1 & - & - & - & 2 & 5,4 \\
\hline & & abscesso & - & - & - & - & - & - & - & - \\
\hline Total & & & 2 & 2 & 1 & - & - & - & 5 & 13,51 \\
\hline \multirow{4}{*}{ II } & \multirow{4}{*}{ scalp } & $\begin{array}{l}\text { deslocamento } \\
\text { do scalp }\end{array}$ & 3 & - & - & - & - & - & 3 & 8,11 \\
\hline & & hematoma & - & 3 & - & - & - & - & 3 & 8,11 \\
\hline & & edema & - & 1 & 1 & 1 & - & - & 3 & 8,11 \\
\hline & & abscesso & - & - & - & - & - & - & - & - \\
\hline Total & & & 3 & 4 & 1 & 1 & - & - & 9 & 24,33 \\
\hline \multirow{4}{*}{ III } & \multirow{4}{*}{ cateter } & $\begin{array}{l}\text { deslocamento } \\
\text { do cateter }\end{array}$ & 3 & - & - & - & - & - & 3 & 8,11 \\
\hline & & hematoma & - & 2 & - & - & - & - & 2 & 5,4 \\
\hline & & edema & - & 1 & 1 & 1 & - & - & 3 & 8,11 \\
\hline & & abscesso & - & - & - & - & - & - & - & - \\
\hline Total & & & 3 & 3 & 1 & 1 & - & - & 8 & 21,62 \\
\hline \multirow{4}{*}{ IV } & \multirow{4}{*}{ scalp } & $\begin{array}{l}\text { deslocamento } \\
\text { do scalp }\end{array}$ & 5 & - & - & - & - & - & 5 & 13,51 \\
\hline & & hematoma & - & 5 & - & - & - & - & 5 & 13,51 \\
\hline & & edema & - & 2 & - & 1 & 1 & - & 4 & 10,81 \\
\hline & & abscesso & - & - & - & - & - & - & 1 & 2,71 \\
\hline Total & & & 5 & 7 & - & 1 & 1 & - & 15 & 40,54 \\
\hline TOTAL & & & 14 & 16 & 3 & 3 & 1 & & 37 & 100 \\
\hline
\end{tabular}


período de observação, cinco $(13,51 \%)$ ocorreram nos animais distribuídos no grupo GI, nove $(24,32 \%)$ nos coelhos que compuseram o grupo GII, oito $(21,63 \%)$ nos pertencentes ao GIII e quinze $(40,54 \%)$ nos coelhos alocados no grupo GIV. Houve uma tendência da estabilidade na fixação dos dispositivos ser menor quando se empregou o esparadrapo. Todavia, quando se avaliou a permanência intravascular, tanto dos cateteres como dos scalps, os resultados obtidos apresentaram-se semelhantes.

Analisando apenas a ocorrência de hematoma (Tabela 2), verificou-se um total de 11 intercorrências, sendo oito $(72,73 \%)$ observadas nos grupos em que o scalp foi utilizado, enquanto o cateter desencadeou apenas três $(27,27 \%)$ dessas complicações. Tal achado é indicativo de que a rigidez do canhão da agulha do scalp pode desencadear traumatismos à parede vascular, com conseqüente extravasamento sanguíneo para o espaço subcutâneo. A mesma tendência foi observada para o edema, já que esta complicação esteve presente em cinco (25\%) coelhos nos quais se utilizou o cateter e, em sete (35\%) animais que tiveram a veia canulada pelo scalp.

O diâmetro da concha auricular no local em que a veia foi canulada variou de 3 a $4 \mathrm{~mm}$, entretanto, nos coelhos, cuja manipulação desencadeou edema, a medida atingiu até $10 \mathrm{~mm}$.

Quanto aos 12 casos que apresentaram edema após remoção dos dispositivos intravenosos, em dois $(16,6 \%)$ dos animais alocados no grupo GII e em três $(25 \%)$ dos coelhos pertencentes ao grupo GIV, a complicação foi considerada grave. Em quatro animais o edema foi classificado como moderado e distribuído de forma igualitária, sendo um em cada grupo. Ainda foi observado um $(8,3 \%)$ caso de intensidade leve nos animais que compuseram o grupo GI e dois $(16,7 \%)$ casos nos coelhos distribuídos no grupo GIII (Tabela 3). Um único caso de abscesso foi diagnosti-

\begin{tabular}{|c|c|c|c|c|c|}
\hline $\begin{array}{l}\text { Dispositivo } \\
\text { empregado }\end{array}$ & Grupo & $\begin{array}{c}\text { Animais que } \\
\text { apresentaram } \\
\text { hematoma }\end{array}$ & Total & $\begin{array}{c}\% \text { animais que } \\
\text { apresentam } \\
\text { hematoma }\end{array}$ & Total (\%) \\
\hline \multirow[b]{2}{*}{ Cateter } & I & 1 & \multirow[b]{2}{*}{3} & 9,09 & \multirow{2}{*}{27,27} \\
\hline & III & 2 & & 18,18 & \\
\hline \multirow{2}{*}{ Scalp } & II & 3 & \multirow{2}{*}{8} & 27,27 & \multirow{2}{*}{72,72} \\
\hline & IV & 5 & & 45,45 & \\
\hline TOTAL & & 11 & 11 & 100 & 100 \\
\hline
\end{tabular}

\begin{tabular}{|c|c|c|c|c|c|c|c|c|}
\hline \multirow{3}{*}{ Grupo } & \multicolumn{8}{|c|}{ Intensidade do edema } \\
\hline & \multicolumn{2}{|c|}{ Leve } & \multicolumn{2}{|c|}{ Moderado } & \multicolumn{2}{|c|}{ Intenso } & \multicolumn{2}{|c|}{ Total } \\
\hline & $\mathbf{N}$ & $\%$ & $\mathbf{N}$ & $\%$ & $\mathbf{N}$ & $\%$ & $\mathbf{N}$ & $\%$ \\
\hline 1 & 1 & 8,3 & 1 & 8,33 & - & - & 2 & 16,66 \\
\hline II & - & - & 1 & 8,33 & 2 & 16,66 & 3 & 25 \\
\hline III & 2 & 16,7 & 1 & 8,33 & - & - & 3 & 25 \\
\hline IV & - & - & 1 & 8,33 & 3 & 25 & 4 & 33,33 \\
\hline TOTAL & 3 & 25 & 4 & 33,33 & 5 & 41,66 & 12 & 100 \\
\hline
\end{tabular}


cado nos coelhos que compuseram o grupo GIV. Neste caso acredita-se que a inquietude do animal após a deambulação, além de ter facilitado a remoção do scalp, resultou em dilaceração da pele e da veia auricular dorsal, propiciando a penetração de microrganismos patogênicos no local. Todas as intercorrências foram solucionadas empregando solução de hipoclorito de sódio a $0,2 \%$ na higienização do local, após a drenagem cirúrgica.

\section{DISCUSSÃO}

Não foram observados na literatura consultada relatos sobre o uso dos cianoacrilatos na fixação de cateteres e scalps intravenosos quando estes foram utilizados na anestesia em coelhos, apesar do princípio ativo despertar nos pesquisadores atenção especial pelo baixo custo e fácil manuseio $[1,4,7,14,15]$. Em estudo comparativo experimental empregando o etilcianoacrilato, o butil-cianoacrilato e o fio de náilon monofilamentar na síntese de pele em ratos, observou-se que o efeito adesivo dos cianoacrilatos na pele desses animais apresentou bons resultados, sendo que os compostos de cadeia mais longa apresentaram menor toxicidade e menor adesividade, sem, contudo, prejudicar o efeito adesivo final [4]. Biópsias executadas em tecidos humanos, após alguns anos de aplicação do cianoacrilato, não revelaram quaisquer evidências de alterações patológicas [9].

O posicionamento, tanto do cateter como do scalp no lúmen vascular e posterior fixação na pele auricular dorsal utilizando o adesivo de cianoacrilato foi rápido e de fácil execução. Porém, considerandose o número de intercorrências observadas foi possível afirmar que o uso do cateter mostrou ser a melhor opção, possivelmente devido a sua maior flexibilidade. Quanto à viabilidade do uso dos dois métodos de fixação, apontou-se vantagens substanciais do éster de cianoacrilato sobre o esparadrapo, especialmente por auxiliar a permanência dos dispositivos por um período maior de tempo. Os cianoacrilatos parecem estimular a cicatrização do epitélio localizado sob o adesivo, sendo eliminados quando a reparação está completa [11]. Alguns autores demonstraram que, na sua degradação, o cianoacrilato é completamente eliminado pelas fezes e não é retido em tecidos ou órgãos vitais, justificando, portanto a escolha do princípio ativo empregado neste estudo [5].
No presente estudo não foi avaliado possíveis alterações patológicas decorrentes do uso do cianocrilato, tendo em vista a ocorrência de sinais clínicos que pudessem ser atribuídos à ação deste princípio ativo. Em outro estudo, foi comparada a histotoxicidade do etil-2-cianoacrilato e buti-2-cianoacrilato em cartilagem de orelha e relatou-se que o butil-2-cianoacrilato resultou em discreta reação inflamatória aguda, mínima reação do tipo corpo estranho e proporcionou um pequeno acúmulo de células gigantes. Todavia, o etil-2 cianoacrilato desencadeou uma reação inflamatória de maior intensidade [13]. Os cianoacrilatos que possuem cadeia menor, como o metil e etil, são histotóxicos e os de cadeia mais longa, butil e isobutil podem não desencadear lesões teciduais, sendo que o butil-2-cianoacrilato é o mais comumente empregado na fixação óssea [2].

$\mathrm{Na}$ literatura consultada, existem relatos afirmando que há dificuldade em se realizar, não apenas a canulação venosa, mas também a manutenção de qualquer dispositivo no lúmen vascular desta espécie seja para aplicação de fármacos anestésicos ou mesmo para quaisquer outras medicações intravenosas, representando uma limitação no emprego destes animais como modelo experimental $[1,7,8]$. Neste estudo, o uso do etil-cianoacrilato como agente auxiliar na fixação, mostrou-se efetivo por propiciar melhor estabilidade aos dispositivos empregados, principalmente o cateter de politetrafluoretileno.

\section{CONCLUSÃo}

Os resultados obtidos neste estudo permitem afirmar que o cateter pode ser utilizado como dispositivo viável na canulação da veia auricular dorsal em coelhos, principalmente fixado por meio da cola à base de etil-cianoacrilato.

\section{NOTAS INFORMATIVAS}

${ }^{1}$ Rompum ${ }^{\circledR}$, Bayer S.A. São Paulo, SP, Brasil.

${ }^{2}$ Vetanarcol®, Konig do Brasil Ltda, São Paulo, SP, Brasil. ${ }^{3}$ Compaz ${ }^{\circledR}$, Laboratório Cristália. São Paulo, SP, Brasil.

${ }^{4}$ Iodopovidona, Brasília, DF, Brasil.

${ }^{5}$ Super Bonder ${ }^{\circledR}$, Henkel Ltda, Itapevi, SP, Brasil.

${ }^{6}$ Solução fisiológica 0,9\% Halextar, Goiânia, GO.

${ }^{7}$ Becker Clorex, Cleaning Solutions Ltda., Santo André, SP, Brasil. 


\section{REFERÊNCIAS}

1 Alves G.E.S. 1984. Emprego do adesivo butil-2-cianoacrilato na redução de feridas cirúrgicas em papilas mamarias de vacas. 43f. Belo Horizonte, MG. Dissertação (Mestrado Medicina Veterinárias) - Programa de Pós-graduação em Medicina veterinária, Faculdade Federal de Minas Gerais.

2 Arun K.G. 2002. The current status of tissue glues: 1. For bone fixation. Plastic Reconstructive Surgery. 7: $2581-2583$.

3 Bonutti P.M., Weikes G.G. \& Andrish J.T. 1999. Isobutyl cyanoacrilate as a soft tissue adhesive. Clinical Orthopaedics and Related Reseach. 225: 241-248.

4 Borba C.C., Roubaud Neto E., Val R.L.R., Borba Jr. C.O., Soufen M.A., Francisco Neto A. \& Sakotani A.Y. 2000. Use of cyanoacrylate as surgical adhesive in rats skin incisions: experimental study. Acta Cirúrgica Brasileira [serial online]. Disponível em: http://www.scielo.br/acta. Acessado em 06/2007 .

5 Bhaskar S.N., Jacoway J.R., Margetis P.M., Leonard F. \& Pani K.C.I. 1966. Oral tissue response to chemical adhesives (cyanoacrylates). Oral surgery, oral medicine, and oral pathology. 22: 394-404.

6 Horsley W.S. \& Miller J.I. 1997. Management of the uncontrollable pulmonary air leak with cyanoacrilate glue. Annals Thoracic Surgery. 63:1492-1493.

7 Kuwahara T., Asanami S., Tamura T. \& Kubo S. 1998. Dilution is Effective in Reducing Infusion Phlebitis in Peripheral Parenteral Nutrition: An Experimental Study in Rabbits. Nutrition. 14: 186-190.

8 Kuwahara T., Asanami S. \& Kubo S. 1998. Experimental infusion phlebitis: tolerance osmolality of peripheral venous endothelial cells. Nutrition. 14: 496-501.

9 Lacaz Netto R., Santos G.M., Macedo N.L., Lima F.R., Santos L.M. \& Okamoto T. 1991. Uso do cianoacrilato na proteção das incisões. Estudo histopatológico comparativo da reparação tecidual em incisões realizadas na pele de ratos, após o uso do metil, do isobutil e do etil-cianoacrilatos (Super Bonder). RGO. 39: 243-248.

10 Monteiro Filho G. 2004. Segredos da estatística em pesquisa científica. Goiânia: Gráfica e Editora Vieira, 188p.

11 Quinn J. 1996. Tissue adhesives. Annals of Emergency Medicine. 27: 531.

12 Silver A. 1976. Tissue adhesives. Veterinary Record. 98: 405-406.

13 Syllos D.H., Silva T.R. \& Malheiros C.A. 1996. Anastomoses intestinais com Histoacryl:comparação entre anastomose com fio, com fio reforçado por Histoacryl, com uso exclusivo de Histoacryl. Estudo experimental em ratos. Revista Médica de São Paulo. 75: 215-231.

14 Toriumi D.M., Raslan W.F., Friedman M. \& Tardy M.E. 1990. Division of facial plastic and reconstructive surgery. Archives of otolaryngolog head \& neck surgery 116: 546-50.

15 Viana F.A.B. 2003. Guia terapêutico veterinário. Lagoa Santa: Editora Cem, 324p.

16 Weber S.C. \& Chapman M.W. 1984. Adhesives in orthopaedic surgey. A review of literature and in vitro bonding strenghts of bone-bonding agents. Clinical Orthopaedics and Related Research. 191: 249-261. 